\title{
Evaluation of Hematological Changes in Tre-En-En and Vitamin C Dietary Supplementation to Wistar Rats
}

\author{
Journal of Medical Clinical Case Reports
}

Research Article

\section{Omoirri $\mathrm{MA}^{1 *}$, Madubogwu NU², Gbagbeke $\mathrm{KO}^{3}$ and Iloh $\mathrm{SE}^{2}$ \\ ${ }^{1}$ Department of Pharmacology and Toxicology, Faculty of Pharmaceutical Sciences, Nnamdi Azikiwe University, Akwa, Anambra State}

${ }^{2}$ Department of Pharmacology and Toxicology, Faculty of Pharmaceutical Sciences, Chukwuemaka Odumegu University Egbariam Anambra State, Nigeria.

${ }^{3}$ Department of Human Physiology, Faculty of Basic Medical Sciences, College of Health Sciences, Delta State University, Abraka, Delta State, Nigeria.

\author{
*Correspondence author \\ Omoirri MA \\ Department of Pharmacology and Toxicology \\ Faculty of Pharmaceutical Sciences \\ Nnamdi Azikiwe University \\ Akwa \\ Anambra State \\ Nigeria
}

Submitted : 16 Dec 2020 ; Published : 16 Jan 2021

\begin{abstract}
In recent times, hematological health indictors have been the focus of most debates, even though several researches on different animal models have been conducted relative to it. In this study, we evaluated the effects of dietary supplementation with Tre-en-en concentrates on full blood count [packed cell volume (PCV), total white blood cell count (TWBCC), total red blood cell (TRBCC) count and total Platelet count (TPC)]. Twenty (20) acclimatized (for two weeks) male rats between 150-200 $\mathrm{g}$ were procured and grouped into four of five rats each. Group I animals were fed with standard rat chow and water ad-libitum (normal control), while group II rats received $5 \mu \mathrm{m}$ each of Tre-en-en grain concentrate daily for five weeks. Whereas, groups III and IV respectively received vitamin C and Tre-en-en $(5 \mu \mathrm{m})+$ vitamin C (Co-administration) daily for five weeks. Following period of administration, animals were euthanized under chloroform anaesthesia and blood sample obtained for haematological analysis. Full blood count was then performed and comparisons made between groups to ascertain the changes in hematological health markers. Results from one-way analysis of variance (ANOVA) showed a statistically significant increase ( $p$ $<0.05)$ in Tre-en-en and Tre-en-en + Vit. C. treated groups (II and IV) compared to control group. Also, Tre-en-en Supplement fed groups (II and IV) showed a statistically significant increase in body weights than control and vit. C. groups (I and III). There was also a statistically insignificant increase $(p<0.05)$ in the PCV of Tre-en-en and Vit. $C$ treated groups (II and III) compared to control, while TWBCC increased insignificantly across groups; whereas TRBCC increased significantly as compared to control. More corroborative works relative to this is recommended to validate the result of this study.
\end{abstract}

Keywords: Hematology, Tre-en-en, Dietary Supplement

\section{Introduction}

In the physiological environment, cell membranes are known to have incessant needs for lipids and sterols in order to stay healthy. Unfortunately, modern grain processing strips lipids, sterols and other vital nutrients from the foods that make up our dietary staples [1]. In addition, important lipids and sterols (good fats) may also be missing from modern diets in which fat substitutes and fat-free items are substituted for foods rich in lipid and sterols [2]. However, certain lipids may increase the fluidity or pliability of cell membranes and help keep cells functioning efficiently by enhancing nutrient utilization in order to promote healthy-energy and vitality [1].

Developed and introduced by Neolife in 1958, Tre-en-en provides phyto-lipids essential to optimal health and cellular function, including omega- 6 and omega-3 fatty acids, and phyto-sterols [3]. It provides critical support for the healthy cellular uptake of nutrients and cellular export of waste and metabolites. Tre-en-en grain concentrates feed the cells with an exclusive whole-food blend of extracts from wheat, rice and

soy. It provides phyto-lipids, including Omega-6 and Omega-3 fatty acids, phyto-sterols beta-sitosterol, gamma-oryzanol, stimasterol, and campesterol, plus octacosanol, and contains no cholesterol [4]. It is cold-pressed and cold processed to preserve nutritional value, as well as improve optimal cell membrane functions.

Tre-en-en has been reported to play an important role in keeping the renal and digestive system healthy, providing the body with plenty omega-3 fatty acids; a major precursor that facilitates the biosynthesis of prostaglandins which are needed to regulate blood coting, hormone production and inflammation due to pain and body swelling (Burr and Miller, 2004). Tre-enen grain concentrates are unique and exclusive blend of whole food concentrates extracted from foods that make up daily staples in the human diets [5].

A 1987 research conducted at Texas University, United States confirmed the nutritional benefits of Tre-en-en grain 
concentrates (Lipids and Sterols from wheat, rice and soya beans). The seven-week studies looked at growth, development, maturation and cardiovascular health of wistar rats fed either a standard control diet or a laboratory chow fortified with Tre-en-en grain concentrates substituted for lipid used in the standard chow group [6]. When the amount of food consumed was correlated with the amount of rat weight gained, study observed Tre-en-en fed animals displayed superior growth and development, indicative that their bodies made better use of available nutrients. In any case, Tre-en-en fed group grew faster, achieved faster maturity and had better overall development than the group fed normal chow; with cardiovascular system showing better development and adrenal activity, an indicator that their energy levels responded better to stress [7]. Although its ameliorative roles on cardiovascular and hematological health indices have been the focus of debates in recent times, albeit, several researches on different animal models have been conducted to ascertain this.

Hematology refers to the study of the numbers and morphology of the cellular elements of the blood - the red cells (erythrocytes), white cells (leucocytes), and the platelets (thrombocytes) and the use of these results in the diagnosis and monitoring of disease [8]. Hematological studies are useful in the diagnosis of many diseases as well as investigation of the extent of damage to blood $[9,10]$. Hematological studies are of ecological and physiological interest in helping to understand the relationship of blood characteristics to the environment and so could be useful in the selection of animals that are genetically resistant to certain diseases and environmental conditions [11, 12]. Hematological parameters are good indicators of the physiological status of animals. Hematological parameters are those parameters that are related to the blood and blood forming organs [13].

Substantive evidences exist that shows that the imbalances in free radical status that necessitates idiopathic blood diseases can be reduced by consumption of antioxidant supplementations, which are also likely found in Tre-en-en [14]. Till this point, the increasing worldwide resort to antioxidant consumption may not be unconnected with recent findings that Omega-3 and Omega-6, which are active ingredients in Tre-en-en, promotes health in numerous body systems with little or no known records on hematological health indicators due to dietary supplementation with Tre-en-en concentrates.

\section{Aim of Study}

This study evaluated hematological the changes in selected haematological indices in Tre-en-en and vitamin c dietary supplementation on wistar rats. Specifically, the study;

1. Determined the effects of Tre-en-en grain concentrate on body weights

2. Investigated the changes in haematological parameters in the administration of Tre-en-en and Vitamin $\mathrm{C}$ to wistar rats

3. Investigated the effect of Tre-en-en supplement on bleeding and clotting times

\section{Materials and Methods}

Study Area: This study was conducted in the animal house of the faculty of basic medical sciences, college of medicine, Ambrose Alli University, Ekpoma, Edo State.

Study Design: Study was designed to be experimental in nature, procuring a total of twenty (20) acclimatized (for two weeks) male rats between 150-200 g were procured and grouped into four of five rats each. Group I animals were fed with standard rat chow and water ad-libitum (normal control), while group II rats received $5 \mu \mathrm{m}$ each of Tre-en-en grain concentrate daily for five weeks. Whereas, groups III and IV respectively received vitamin $\mathrm{C}$ and Tre-en-en $(5 \mu \mathrm{m})+$ vitamin $\mathrm{C}$ (Co-administration) daily for five weeks.

Tre-en-en Preparation: A capsule of Tre-en-en grain concentrate is known to contain $675 \mathrm{mg}$ in standard dose. This was aspirated into a $2 \mathrm{ml}$ syringe to obtain the volume per capsule. From the recommended dose of Tre-en-en (1 capsule 3 times daily), volume was obtained (in $\mathrm{ml}$ ) and administered in accordance with the body weight of each rat. Here, approximately 5 microliters were administered daily to each rat (using a dropper) for a period of 5 weeks.

Determination of Weight: Animal weights were measured in grams (g) using an electronic weighing scale (Cardinal Scale Manufacturing Co., Webb City, MO). For each group, body weights were obtained and recorded weekly throughout the duration (five weeks) of administration of test substances

Sample Collection: At the end of the period of administration, animals were euthanized by cervical decapitation and blood collected from the superior vena cava using a $5 \mathrm{ml}$ syringe. Obtained sample was then centrifuged at 3000rpm for 15 minutes and the sera collected and stored in a refrigerator at $-20 \mathrm{oC}$ for hematological analysis.

\section{Hematological Assay}

Packed Cell Volume (PCV): Collected blood was first heparinized, then centrifuged at a speed of 11000 revolutions per minute (rpm) for 5 minutes. RBCs packed at the bottom formed the packed cell volume, while plasma remained above this. This was then read as the PCV value, using the microhematocrit reader.

Total White Blood Cell (TWBC) Count: TWBC count was achieved by the method of Ramnick, (2003) after blood sample collection and dilution at 1:5 with Turks solution (1\% glacial acetic acid). Diluted sample was then being loaded into an improved Neuber counting chamber with the aid of a capillary tube, while counting the TWBC from appropriate squares in the chamber using a microscope.

Total Red Blood Cell (TRBC) Count: Total RBC count was performed with the method of Chesbrough, (2000). Obtained blood sample was diluted at 1:20 with Hayen's fluid ( $\mathrm{HgCl} 2$ $0.05 \mathrm{~g}$; $\mathrm{Na} 2 \mathrm{SO} 42.5 \mathrm{~g} ; \mathrm{NaCl} 5 \mathrm{~g}$ in $100 \mathrm{ml}$ of water). Diluted sample was then loaded into the improved Neuber counting chamber using the Pasteur pipette. Next, RBC was counted from the squares within the chamber using the light microscope. 
Platelet Count: Counting platelets is reportedly done by measuring $380 \mu \mathrm{l}(0.38 \mathrm{ml})$ of filtered ammonium oxalate diluting fluid into a small test tube. Next, about $20 \mu \mathrm{l}(0.02$ $\mathrm{ml}$ ) of well-mixed anticoagulated blood was then filled into the improved Neubaeur counting chamber, mixed, and left undisturbed for 20 minutes. Next, the underside of the chamber was dried with cotton wool and viewed under the microscope to count platelets.

Clotting Time: The clotting time was estimated by method of Lee and White. In this method, a drop of collected blood sample was placed on the dry glass slide. From the time of the drop being placed, the slide was then tilted at an angle of 450 at 30 seconds interval till there appeared to be no change in the shape of the blood drop on being tilted at an angle of 1800 . This time was then noted as the clotting time.

Results
Bleeding time: This was determined by Duke's method. Here, the tail of the rat was pricked (with a lancet) and the time of prick noted. The oozing blood was then mopped with a filter paper at an interval of 30 seconds till the time bleeding stopped. This was then read and recorded as the bleeding time.

Ethical Clearance: Ethical approval was sought from the Research and Ethics Committee of the College of Medicine, Ambrose Alli University, Ekpoma, Edo State, Nigeria.

Statistical Analysis: Obtained results were represented as mean standard deviation. Statistical analysis was done using the one-way analysis of variance (ANOVA) and post-hoc (tukey) test. Statistics was carried out with a graph pad prism software (version 8.0). A p-level less than 0.05 was considered as statistically significant.

\begin{tabular}{|c|c|c|c|c|c|c|}
\hline \multirow[t]{2}{*}{ Treatments Groups } & \multicolumn{4}{|c|}{ Body Weights } & \multirow{2}{*}{$\begin{array}{l}\text { ANOVA } \\
\text { (p-value) }\end{array}$} & \multirow[t]{2}{*}{ Remark } \\
\hline & IBW & $14^{\text {th }}$ day & $28^{\text {th }}$ Day & FBW & & \\
\hline Control (I) & $184.20 \pm 5.98$ & $186.60 \pm 9.07$ & $185.20 \pm 7.05$ & $186.20 \pm 7.50$ & 0.7002 & Insig. \\
\hline II & $176.80 \pm 9.76$ & $184.0 \pm 39.29$ & $180.80 \pm 41.17$ & $195.00 \pm 19.82$ & 0.0007 & Sig. \\
\hline III & $171.80 \pm 7.56$ & $173.60 \pm 49.30$ & $172.80 \pm 87.79$ & $174.60 \pm 71.51$ & 0.5101 & Insig. \\
\hline IV & $167.00 \pm 9.92$ & $172.20 \pm 16.96$ & $181.60 \pm 17.76$ & $190 \pm 25.13$ & 0.0005 & Sig. \\
\hline
\end{tabular}

Table I: Comparative Body Weights in Tre-en-en Supplementation Feeding

Results are presented as mean \pm SEM. From the table, Tre-en-en Supplement fed groups (II and IV) showed a statistically significant increase in body weights than control (group I) and vit. C. group (group III).

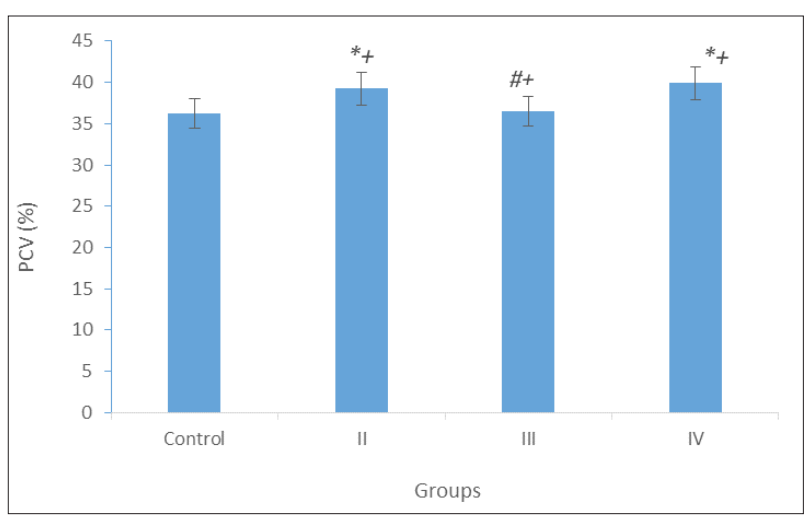

Figure 1: Comparative Changes in PCV in Tre-en-en Supplementation Feeding

* = Significant, $\#=$ Insignificant, $+=$ Increase, $-=$ Decrease. Student $t$-test returned a statistically significant increase $(p<0.05)$ in Treen-en and Tre-en-en + Vit. C treated groups (II and IV) compared to control group

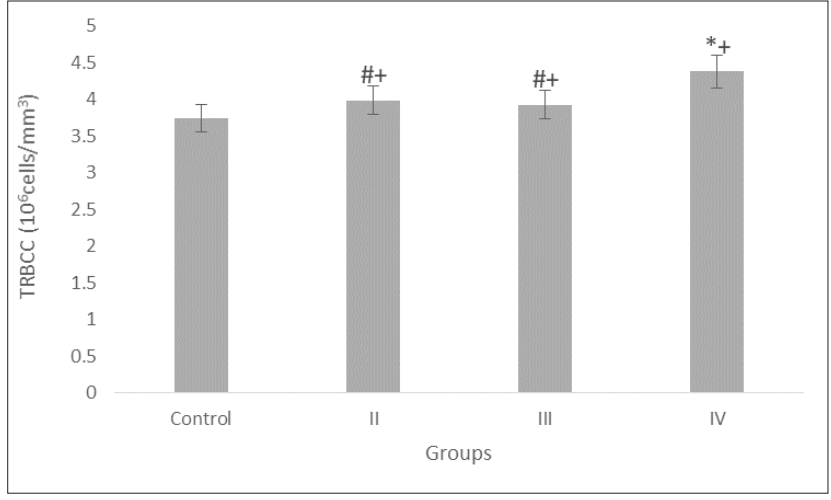

Figure 2: Comparative Changes in Total Red Blood Cell Count (TRBCC) in Tre-en-en Supplementation Feeding

* = Significant, \# = Insignificant, + = Increase, - = Decrease. Student t-test proved to a statistically insignificant increase $(p<0.05)$ in Treen-en and Vit. C treated groups (II and III). This increase was however significant for group IV rats (compared to control group) following Treen-en + Vit. C co-administration 


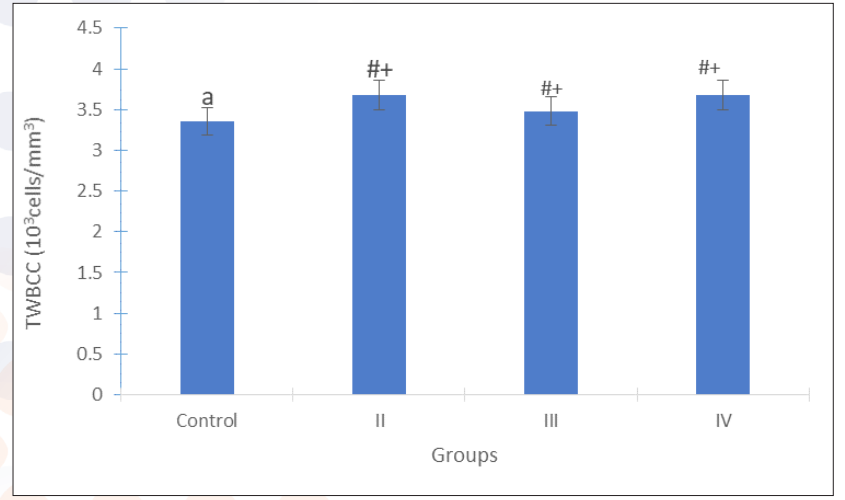

Figure 3: Comparative Changes in Total White Blood Cell Count (TWBCC) in Tre-en-en Supplementation Feeding

$\#+=$ Insignificant increase $(p>0.05)$. Here, it is noticed that TWBCC increased upon comparison. These increases were however insignificant across groups as compared with control

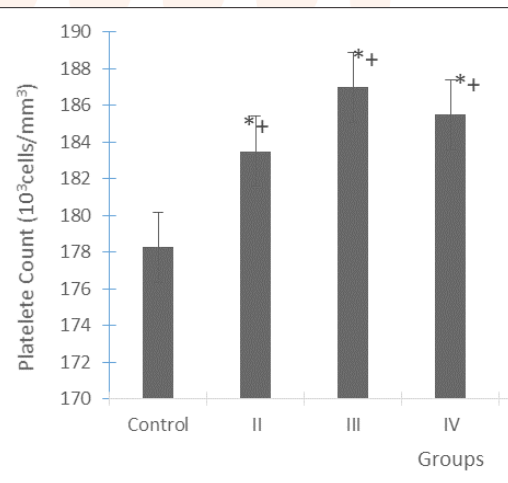

Figure 4: Comparative Changes in Total Platelet Count (TPC) in Tre-en-en Supplementation Feeding

$*_{+}=$Significant increase $(p<0.05)$. From above chat, it is seen that TPC increased significantly across groups following comparison with control

\begin{tabular}{|l|l|l|l|}
\hline S.No & $\begin{array}{l}\text { Treatment } \\
\text { Groups }\end{array}$ & \multicolumn{2}{l|}{ Time (Sec.) } \\
\hline & $\begin{array}{l}\text { Bleeding } \\
\text { Time }\end{array}$ & Clotting Time \\
\hline 1 & Control & $47.64 \pm 1.96$ & $124.72 \pm 1.32$ \\
\hline 2 & II & $92.41 \pm 1.14^{*}$ & $170.53 \pm 1.12^{*}$ \\
\hline 3 & III & $58.14 \pm 1.62^{*}$ & $138.74 \pm 0.78^{*}$ \\
\hline & IV & $56.60 \pm 1.21^{*}$ & $156.58 \pm 1.16^{*}$ \\
\hline
\end{tabular}

Table 2: Effects of Tre-en-en Supplementation Feeding on Bleeding and Clotting Time

$*=$ All values are represented as mean \pm SEM. From the table above, Tre-en-en Supplementation in wistar rats caused a statistically significant increase in bleeding and clotting times of experimental than control animals.

\section{Discussion}

Body cells are surrounded by special membranes that allow for in-flow of nutrients and out-flow of metabolic wastes. Tentatively, starving these cellular membranes of vital nutrients like lipids and sterols makes them inflexible and fail in performing their very critical functions. Albeit, whole grain lipids and sterols; if supplemented in dietary sources could be available to allow cells regain their flexibility and perform optimally in the delivery of nutrients in and out of the cells. In this study, hematological changes in tre-en-en (a lipid and sterol rich dietary supplement) and vitamin $\mathrm{C}$ was investigated wistar rats over a period of five weeks. First, a total of Twenty (20) adult male wistar rats of between 150-200 $\mathrm{g}$ were procured, acclimatized (for two weeks) and grouped into four (4) groups of five rats each $(n=5)$. While group I animals received standard rat chow and water at liberty (normal control), group II rats were daily fed $5 \mu \mathrm{m}$ each of Tre-en-en grain concentrate for a total of five weeks. Whereas, groups III and IV were respectively fed with vitamin $\mathrm{C}$ and Tre-en-en $(5 \mu \mathrm{m})+$ vitamin $\mathrm{C}$ (Co-administration) daily for five weeks; following which animals were euthanized under chloroform anaesthesia and blood sample obtained for haematological analysis. After sample collection, hematological tests; packed cell volume (PCV), total white blood cell count (TWBCC), total red blood cell (TRBCC) count and total Platelet count (TPC) were then performed to determine the changes due to administration of test substances.

Table I of the results obtained shows a comparative effect of tre-en-en supplementation feeding on the body weights of animals across groups. From the table, tre-en-en supplement fed groups (II and IV) showed a statistically significant ( $p>$ 0.05 ) increase in body weights than control (group I) and vit. C. group (group III). Again, the packed cell volume (PCV) was noticed to have increased significantly $(\mathrm{p}<0.05)$ across groups (Figure I), except for group III which returned and insignificant increase as compared to control. This implies that vitamin $\mathrm{C}$ co-administration with tre-en-en caused less improvement in PCV than single dose administration of tre-en-en or vitamin C, even those this improvement was insignificant. One possible explanation for this may be lack of compatibility between treen-en and vitamin $\mathrm{C}$ when co-administered. This is known as drug-drug interaction, and portends an antagonistic effect of one drug against the efficacy of the other.

Also a look at figure II shows the comparative changes in total red blood cell count (TRBCC) in tre-en-en supplement feeding across groups. Different hematological changes have been associated with different blood conditions such as anaemia, following treatment with different drugs. Most of these reports have been found to involve red blood cells, leukocytes and thrombocytes [15-17]. The reports on the effects of low $\mathrm{RBC}$ on hematological parameters have been conflicting for instance. Ani et al., (2016) reported a lower packed cell volume PCV, monocyte counts and the lymphocytes for malariainduced anemia positive individuals, with contrary reported for total leucocyte counts, neutrophil counts, basophils and eosinophil counts. In this study figure (II-IV) almost all assayed parameters seemingly had a significant increase than control in the administration of tre-en-en supplement, student t-test proved to a statistically significant $(\mathrm{p}<0.05)$ increase in TRBCC for Vit. C treated group (IV). This increase was 
however insignificant for groups II and III rats (compared to control group) following Tre-en-en or Tre-en-en + Vit. C administration, the implication of this is that Tre-en-en has a positive effect on TRBCC be it given as a single dose or with vitamin C.

Again, table II shows the effects of tre-en-en supplementation feed on the bleeding and clotting time of animals in this study. From the table above, Tre-en-en Supplementation in wistar rats caused a statistically significant increase $(\mathrm{p}<0.05)$ in bleeding and clotting times of experimental than control animals. This proves it to be a potent anti-hemorrhagic food supplement for the control of excessive bleeding. Though no new study is currently available to support or oppose this finding, however, this action is probably achieved via the activation of the extrinsic and/or intrinsic clotting pathways to facilitate the timely release of blood clotting factors; which are vital for the formation and activation of platelet meshwork. This effect also probably accounts for the reason for a significant increase $(p<0.05)$ in TPC; key component of blood that initiates clot formation during severe bleeding.

\section{Conclusion}

In this study, administration of tre-en-en supplement to wistar rats caused an unexpected, but statistically significant increase in most haematological parameters assayed, with PCV returning and insignificant decrease in group III (tre-enen + vitamin C treated group). The effect of test substance also caused a statistically significant increase in the bleeding and clotting times of animals as compared to control group.

\section{References}

1. GNLD (2009) A better way of life. www.gnld.com

2. Meyers CD, Kamanna VS, Kashyap ML (2004). "Niacin therapy in atherosclerosis". Current opinion in lipidology, 15: 659-665.

3. Akpantah AO, Oremosu AA, Ajala MO, Noronha CC, Okanlawen AO (2003). Nig J Health Biomed sci, 2: 40-46.

4. Burr GO, Miller E (2010). "on the nature and role of the fatty acids essential in nutrition (pdf). J Bio Chem, 86.

5. Olaleye SB, Faromb EO, Adweoye EA, Owoyele BV, Onasanwo SA, et al. (2000). Plasma Lipids and their role in disease. Africa journal of biomedical research 3: 174.

6. Churchil livingstone: medical dictionary (1999). Royal Society of Medicine 1999: 119-126.

7. Guyton and Hall: medical physiology (2005). 10th ed, The heart and its function; Pub: Elsevier Ltd, 9: 96-133.

8. Merck Manual (2012). Hematologic reference ranges. Mareck Veterinary Manual. Retrieved from http://www. merckmanuals.com/.

9. Onyeyili PA, Egwu GO, Jibike GI, Pepple DJ, Ohaegbulam JO (2002). Seasonal variation in haematological indices in the grey-breasted guinea fowl (Numida mealagris Gallata pallas). Nigerian Journal of Animal Production, 18: 108110.

10. Togun VA, Oseni BSA, Ogundipe JA, Arewa TR, Hammed
AA, et al. (2007). Effects of chronic lead administration on the haematological parameters of rabbits - a preliminary

11. Ovuru SS, Ekweozor IKE (2004). Hematological changes associated with crude oil ingestion in experimental rabbits. African Journal of Biotechnology 3: 346-348.

12. Mmereole FUC (2008). The Effects of Replacing Groundnut Cake with Rubber Seed Meal on the Hematological and Serological Indices of Broilers. International Journal of Poultry Science 7: 622-624.

13. Bamishaiye EI, Muhammad NO, Bamishaiye OM (2009). Hematological parameters of albino rats fed on tiger nuts (Cyperus esculentus) tuber oil meal-based diet. The International Journal of Nutrition and Wellness 10.

14. Herraiz Tomas, Chaparro Carolina (2016). "Human monoamine oxidase enzyme inhibition by coffee and $\beta$-carbolines norharman and harman isolated from coffee".

15. Layla AM, Bashawri FCP, Ahmed A, Mandil PH, Ahmed $\mathrm{AB}$, et al. (2002). Malaria: Haematological aspects. Annals of Saudi Medicine, 22: 5-6.

16. Maina RN, Walsh D, Gaddy C, Hongo G, Waitumbi J, et al. (2010). Impact of Plasmodium falciparum infection on haematological parameters in children living in Western Kenya. Malaria Journal 9: 54.

17. Imoru M, Shehu AU, Ihesinlor GU, Kwaru HA (2013). Haematological changes in malaria infected children in North-West, Nigeria. Turkish Journal of Medical Sciences, 43: 838-842.

Copyright: C2021 Omoirri MA. This is an open-access article distributed under the terms of the Creative Commons Attribution License, which permits unrestricted use, distribution, and reproduction in anymedium, provided the original author and source are credited. 